\title{
Bart Geurts* \\ Communication as commitment sharing: speech acts, implicatures, common ground
}

https://doi.org/10.1515/tl-2019-0001

Abstract: The main tenet of this paper is that human communication is first and foremost a matter of negotiating commitments, rather than one of conveying intentions, beliefs, and other mental states. Every speech act causes the speaker to become committed to the hearer to act on a propositional content. Hence, commitments are relations between speakers, hearers, and propositions. Their purpose is to enable speakers and hearers to coordinate their actions: communication is coordinated action for action coordination. To illustrate the potential of the approach, commitment-based analyses are offered for a representative sample of speech act types, conversational implicatures, as well as for common ground.

Keywords: commitment, speech acts, common ground, conversational implicatures

\section{Introduction}

The principal units of human communication are speech acts: promises, orders, reminders, and so on. But what are speech acts? Basically, there are two ways of answering that question. Consider a perfectly mundane domestic episode: by uttering the sentence "I'll do the dishes", Barney promises Betty to do the dishes. One way of construing Barney's utterance is that it serves to express Barney's intention to do the dishes. On this construal, understanding speech acts requires that one take a mentalist perspective, for their purported purpose is to convey information about what's on the speaker's mind. Alternatively, we can take a social perspective and say that the purpose of Barney's promise is to undertake a commitment to Betty: as a result of saying, "I'll do the dishes", Barney becomes committed to Betty to do the dishes.

\footnotetext{
*Corresponding author: Bart Geurts, Faculteit der Filosofie, Theologie en Religiewetenschappen, Radboud Universiteit Nijmegen, Postbus 9103, 6500 HD Nijmegen, The Netherlands; Higher School of Economics, Moscow, Russia, E-mail: brtgrts@gmail.com
} 
These two stances do not necessarily exclude one another, and some theories seek to accommodate both, but in general the emphasis is on the psychological rather than the social aspects of communication, and in fact the view that human communication is essentially a form of "mind reading" holds sway in large parts of pragmatics, the cognitive sciences, and the philosophy of mind. It is well known, however, that such an approach raises developmental issues. If understanding a promise is primarily a matter of comprehending the speaker's intentions, children must be able to attribute intentions before they can understand promises. But how likely is it that two-year olds have this skill, and how do they learn to attribute intentions and other psychological states if not through communication?

Since there are no working models of how children might learn to attribute mental states before they start dealing with speech acts, it is tempting to stipulate that mental-state attribution doesn't have to be learned in the first place: it's in the genes. But this flight into nativism merely passes the buck from development to evolution, and the same questions that arose with respect to the ontogeny of communication and mental-state attribution now arise with respect to their phylogeny.

In this paper I take the view that communication is, first and foremost, a matter of negotiating social commitments. This shift in emphasis is motivated in part by the expectation that a commitment-based approach offers a sounder basis for understanding language learning and evolution than a mentalist approach. However, I believe it is also of interest in its own right to see how much explanatory mileage we can get out of a commitment-based account. In a nutshell, that is the project of this paper, and although it is intended as a prelude to theories of learning and evolution, developmental and evolutionary issues will be touched upon only superficially. My main goal is to make a case for the claim that social commitments are the fulcrum of communication.

I believe it is uncontroversial to say that any theory of communication will have to deal with at least the following topics: speech acts, common ground, linguistic conventions, and pragmatic inference. To this list I would like to add a fifth item: a theory of communication should bring together the social and mentalist perspectives in a way that is significantly more enlightening than the mere acknowledgement that these two perspectives exist. In this paper I will consider four of these topics, and show what a commitment-based approach has to offer in each case. Speech acts and common ground come to the fore in Section 3 and Section 4, respectively; Section 5 is about pragmatic inference and the connection between social and mentalist aspects of communication. Linguistic conventions will not be discussed here, but in Geurts (2018a) I present an account of conventions that complements the story of this paper. 


\section{Coordination and commitment}

Being the ultrasocial species that we are, we are in constant need of having to coordinate our actions so that we can play football, have conferences, do the dishes together, live in the same house, build rockets, fight each other in court, and so on. Our interactions unfold in time, often long stretches of it, and playing it by ear is generally a poor strategy. Einstein is alleged to have said that "the best preparation for the future is to live as if there were none", but if he did say that, he was wrong. We wouldn't get anything done if we stopped planning for the future.

Our social interactions, in particular, are unthinkable without advance planning, and if others couldn't be counted upon to do their parts, joint plans wouldn't be possible. That's why we make commitments: we commit ourselves to act as goalkeeper or umpire, to chair a session or give a talk, to wash or dry the dishes, and so on. Making commitments is a form of expectation management; it is a way of permitting others to rely on us to act in certain ways, so that they can coordinate their activities with ours. These activities may but need not involve common goals. For example, living in the same building calls for coordination between tenants, but that does not necessarily imply that they share a common goal, except perhaps a very general one, which is achieved mainly by refraining from, rather than engaging in, certain kinds of activities.

While commitments sometimes come about implicitly, they may also be negotiated explicitly. That's what communication is for, and promises are the paradigm case. If Albert promises Brenda to do the dishes, he commits himself to do the dishes, and by the same token Brenda becomes entitled to act on the assumption that Albert will do the dishes. Assertions, too, create commitments. If Brenda informs Albert that she is pregnant, implying that he is the father, they will typically end up being mutually committed in a bewildering variety of ways, all of which spring from Brenda's initial commitment, brought about by her assertion, to act on the assumption that she is pregnant. In the following I explore the hypothesis that the chief purpose of speech acts is to enable speakers to share commitments that enable them to coordinate their actions: communication is coordinated action for action coordination. This hypothesis is meant to hold not only for promises and assertions, but across the illocutionary board.

The concept of commitment has been used widely and variously in the philosophy of language, rhetoric, speech act theory, and formal theories of dialogue. The theory proposed here borrows ideas from many sources, notably Hamblin (1971), Brandom (1994), Kibble (2006a, 2006b), and Krifka (2015) (see De Brabanter and Dendale 2008 for a survey of the commitment literature). On my account, commitment is a three-place relation between two individuals, $a$ and $b$, and a propositional content, $p$ : $a$ is committed to $b$ to act on $p$, or $C_{a, b} p$ for 
short. So, if Albert promises Brenda to do the dishes, then as a result of Albert's promise: $C_{a, b}$ (a will do the dishes). To say that $a$ is committed to $b$ to act on $p$ is to say that $a$ is committed to $b$ to act in a way that is consistent with the truth of $p$. I take this to entail that $b$ is entitled by $a$ to act on $p$, and should $b$ wish to act on $p$, and $p$ turn out false, then $b$ may hold $a$ responsible for the consequences. Hence, commitment is a normative concept. It belongs to the same family of relations as obligation, duty, and responsibility, all of which are primarily directed towards others. That is, commitments are social relations first and foremost, not psychological states: $a$ can be committed to act on $p$ without suspecting that he is thus committed, and indeed without even entertaining the possibility that $p$.

Brenda's announcement, "I'm pregnant", causes her to become committed to act on the proposition «Brenda is pregnant》. In principle, this commitment constrains any acts Brenda may consider, including her speech acts. In fact, commitments often reveal themselves chiefly by constraining one's communicative dispositions. To vary the example, if Brenda asserts that ancient Sparta was a republic, there may be little if anything in her practical behaviour to show for her commitment to act on $\llbracket$ Sparta was a republic $\rrbracket$, but in her communicative behaviour it will manifest itself by a willingness to reaffirm and defend that Sparta was a republic, to omit Sparta when listing the monarchies of ancient Greece, to baulk at references to the kings of Sparta, and so on.

Since, by definition, propositional attitudes are relations between individuals and propositions, commitment is a propositional attitude of sorts, but it is a threeplace relation between pairs of individuals and propositional contents (cf. Singh 2000). Thus commitments are relativised to others in a way that psychological attitudes are not. This feature enables us to undertake conflicting commitments, with or without impunity. Having just promised Albert to marry him, Brenda goes on to make the same promise to Clyde. That's not nice of Brenda, since at least one of her suitors is bound to be disappointed (assuming, if only for example's sake, that bigamy is not an option). Nevertheless, everything is in order from a communicative point of view: Brenda has successfully undertaken two commitments, albeit conflicting ones. Compare this with a scenario in which Brenda promises Albert to marry him and Clyde. That would be communicative misconduct: one cannot be committed to one and the same person to bring about an impossible state of affairs.

Though one can believe and even know what one is committed to, commitments as such are neither psychological nor epistemic. This has important consequences for the logic of commitment. For example, it is a contested issue in the logic of belief whether or not beliefs are closed under entailment: if $a$ believes $p$ and $p$ entails $q$, does it follow that $a$ believes $q$ ? Although the answer 
is clearly "No", belief logics typically stipulate that belief is closed under entailment, excusing this postulate as a convenient "idealisation" (whatever that may mean). Compared to belief, the case of commitment is straightforward: if $C_{a, b} p$ and $p$ entails $q$, then $C_{a, b} q$. If Albert commits himself to act on $\llbracket$ Oxygen is heavier than nitrogen $\rrbracket$, he thereby also becomes committed to act on $\llbracket$ Nitrogen is lighter than oxygen $\rrbracket$. He may not realise that he is thus committed, but that doesn't alter the fact that he is. By undertaking a commitment, a speaker ipso facto undertakes any further commitments flowing from it. In this respect, commitment is in the same boat as other normative notions, like permission, obligation, and so on.

It is in the nature of commitments that they are relatively stable, for otherwise they couldn't serve their purpose of enabling action coordination (cf. Bratman 1987 on what he calls "inertia"). This is not to say that commitments are written in stone. Occasionally, we break commitments due to unforeseen circumstances, negligence, or forgetfulness. Also, a commitment may be retracted expressly: I promised my spouse to buy coffee on my way home, but my car broke down, and therefore I have to renege on my promise; or, I told my son that Napoleon was fiftytwo when he died, but discover I was mistaken, and therefore correct myself. ${ }^{1}$ In such cases, commitments persist up to the point at which they are withdrawn. Once undertaken, a commitment holds in the present (I am committed now to buy coffee on my way home), and persists by default.

Thus far I have spoken about commitment as a social relationship subserving action coordination between individuals. But each of us must coordinate his own actions, too, and as Bratman (1987) has emphasised, interpersonal and intrapersonal coordination are closely related:

To achieve complex goals I must coordinate my present and future activities. And I need also to coordinate my activities with yours. Anyone who has managed to write a lecture, pick up a book at the library, attend a committee meeting, and then pick up a child at school will be familiar with the former type of intrapersonal coordination. And anyone who has managed to arrange and participate in a committee meeting with several colleagues will be familiar with the latter sort of interpersonal coordination. (Bratman 1987: 2)

Just as we make commitments to others so as to coordinate our actions with theirs, we make commitments to ourselves to coordinate our own actions. Thus commitment has two faces: a social and a private one. Given $C_{a, b} p$, let's say $a$ 's commitment is "social" if $a \neq b$, and "private" if $a=b$. I undertake a private commitment, for example, when I decide to read Moby Dick, have muesli for breakfast,

1 MacFarlane (2011) argues that retractability is a problem for several mainstream theories of assertion. His arguments hold for other speech acts, too. 
or buy a new shirt. It might be thought that social and private commitments are very different beasts, but as they serve the same purpose, i.e. action coordination, and do so in similar ways, it makes sense to pursue a unified view on commitment; which is what I will do. That said, since this paper is about communication as an interpersonal activity, social commitments will be in the limelight, though private commitments will play a significant supporting role in the analysis of conversational implicatures (Section 5).

To sum up, my concept of commitment is a big tent in two respects. First, since action coordination is a concern that straddles the traditional divide between the individual and the social, the same goes for commitment as I understand it. Secondly, I contend that all speech acts are alike in that they cause commitments for the speaker, and that a major part of communicative interaction can be explained in these terms. In the following I try to provide support for these claims.

\section{Speech acts}

Even if the vast literature on speech acts is rife with conflicting opinions, observations, and terminology, there is a broad consensus on what the major speech act types are (cf. Kissine 2013b). They are three: commissives (e.g. promises), directives (e.g. requests), and constatives (e.g. assertions). ${ }^{2}$ Questions are usually treated as requests for information, and therefore classified with the directives. There is less agreement on the speech acts falling outside the major categories, which mainly consist of expressive and conventional uses (e.g. respectively, "Ouch!” and "I baptise thee 'Oliphant' ").

The purpose of this section is to provide commitment-based analyses of a representative sample of all the major and minor speech act types. I don't intend to defend this or any other taxonomy of speech acts, nor do I intend to provide definitions of any speech act type or subtype. Those have been objectives of many studies on speech acts, but they aren't mine, and to be honest, I doubt that they are viable goals in the first place. My aim is merely to show that a commitmentbased account can elucidate the workings of a fair selection of speech act types, and thus support my claim that commitment is at the heart of communication. ${ }^{3}$

2 My use of the labels "commissive", "directive", and "constative” is in line with that of Bach and Harnish (1979) and Kissine (2013a), among others, and seems to be fairly common.

3 Although commitment is by no means an obscure concept, there have been relatively few attempts to apply it across more than one or two speech act types (especially promising and assertion). Exceptions are Gazdar (1981), Singh (2000), Kibble (2006a, 2006b), Beyssade and Marandin (2009), and Lauer (2013). 
Let's start by comparing and contrasting three examples, one for each of the major speech act types, supposing in each case that Alfred addresses Bertha:

(1) I'll walk the dog.

[commissive]

(2) Could you close the door, please? [directive]

(3) Your sister called. [constative]

In a normal run of events, by uttering one of these sentences, Alfred undertakes a commitment whose propositional content is «Alfred will walk the dog , in the

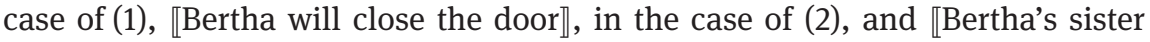
called】, in the case of (3). These propositions diverge in several ways, the most important of which is that the first two specify a goal of Alfred's (his commitment is telic), whereas the third one does not (so Alfred's commitment is atelic). ${ }^{4}$ The telltale difference between (1) and (2) concerns who must see to it that Alfred's goal is achieved, which in the former case is Alfred himself, while in the latter it is Bertha. Crucially, however, in each of these cases Alfred's commitment is to act in accordance with the propositional content in question, regardless whether it is telic or not. Although this may be less obvious in the second example, it seems to me that, as a rule, Alfred will ask Bertha to close the door only if he is reasonably sure that she will do so, and if he isn't sure and pleading with Bertha to close the door, he may be committing himself to act on «Bertha will close the door $\rrbracket$ in order that Bertha make it true. (More on this topic in Section 3.2.)

Generalising boldly from these examples, I propose that:

$i$. Every speech act $S$ addressed by $a$ to $b$ causes a commitment $C_{a, b} p$.

ii. If $S$ is constative, $a$ 's commitment is atelic.

iii. If $S$ is commissive, $a$ 's commitment is telic and $p$ will not be true unless $a$ sees to its truth.

$i v$. If $S$ is directive, $a$ 's commitment is telic and $p$ will not be true unless $b$ sees to its truth.

These statements are not to be understood as attempts at defining speech act types, or even merely to specify some of the necessary conditions for being a constative, commissive, or directive. Rather, they are intended as rough and ready generalisations which still have to prove their mettle, and in that spirit I will elaborate and defend them in the following.

It is not uncommon for theories of speech acts to distinguish between commitment to the truth of a proposition $p$ and commitment to make $p$ true, and to

4 It is sometimes supposed that goals are psychological entities, but that is not how I understand the term, and I believe that my understanding agrees with everyday usage: we freely attribute nutritional and procreational goals to bees, bats, and even bacteria, but it is doubtful that all or any of these creatures have minds. 
associate these two types with assertions and promises, respectively (e.g. Brandom 1994, Walton and Krabbe 1995, Beyssade and Marandin 2009). In the same vein, Searle (1975) famously took Anscombe's (1957) notion of "direction of fit" to separate constatives, whose illocutionary point is to get their propositional content to fit the world, from commissives and directives, whose direction of fit is world-to-content. My telic/atelic dichotomy is similar to these distinctions, but different from both, in two main respects.

First, and most importantly, on my understanding, a commitment is always a commitment only to act in ways that are consistent with the truth of a given proposition $p$. Telic commitments just have a special feature that atelic commitments lack, in that they represent speakers' goals. If Alfred is committed to the goal of making breakfast, then he is committed to act on $\llbracket$ Alfred will make breakfast $\rrbracket$. Alfred may doubt that he will be able to make breakfast, and even be convinced that he won't be, but in either case his commitment to Bertha will be unaffected. And Bertha, for her part, may doubt Alfred's ability to make breakfast so much that she decides not to act on $\llbracket$ Alfred will make breakfast $\rrbracket$; but that doesn't alter the fact that she is entitled, by Alfred, to act on that proposition.

Second, I assume that the speaker may be committed to a goal that can only be realised by the addressee, which entails that my notion of commitment to a goal $p$ is broader than that of commitment to make $p$ true. Thus it becomes possible to hold that directives are like commissives in that they commit the speaker to a goal, even if that goal can only be realised by the addressee.

In the remainder of this section we will have a closer look at each of the three major speech act types (Sections 3.1-3.3), as well as some minor ones (Section 3.4), developing the foregoing sketch as we proceed.

\subsection{Commissives}

In their 1979 monograph, Bach and Harnish noted that commissives are the only type of speech act for which Austin's (1962) label had been universally retained (Bach and Harnish 1979: 49). That observation still seems to hold. Commissives are also the speech acts for which a commitment-based analysis is the most widely accepted. Besides promises, commissives are usually taken to include threats, offers, bids, and bets. Commissives are so-called because they commit the speaker to the goal of making $p$ true. In the simplest cases $p$ represents a future act or state of the speaker's, as in "I'll deal with it" or "I'll be there." But "Clyde will be there" may count as a promise, too, and if it does, the speaker undertakes to see to it that Clyde will be there. A typical promise presents $p$ as good for the addressee; a threat presents $p$ as bad. 
Offers are standardly classified as commisives, but Alfred's offer to wear a tie only commits him to wear a tie if Bertha accepts his offer. In an attempt to accommodate this observation, Bach and Harnish (1979: 49-50) define commissives as "acts of obligating oneself or of proposing to obligate oneself to do something specified in the propositional content". However, this breaks the unity of the class: just as eating kelp and proposing to eat kelp are different things altogether, committing oneself to wear a tie is not at all the same thing as proposing to commit oneself to wear a tie. Unity is restored by conditionalising the propositional content of the speaker's commitment. Let $p$ be $\llbracket$ Alfred will wear a tie $\rrbracket$. Then Alfred's commitment is of the form $C_{a, b}\left(\left(C_{b, a} p\right) \rightarrow p\right)$, i.e. Alfred is committed to a conditional goal, which entails that he becomes committed to wear a tie if and

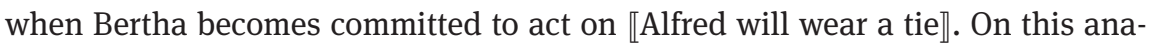
lysis, offers are conditional promises, and Alfred's offer is not very different from, "I'll wear a tie if you do." Bids, bets, and threats, too, are usually conditional, often explicitly so.

Conditional speech acts have had a somewhat troubled history, which is nicely summed up by Walker's (1975: 145) rhetorical question: "How can one perform a speech act in a conditional way, any more than one can stand on one's head in a conditional way?" Walker's puzzle dissolves if we analyse conditional speech acts as creating commitments to act on conditional propositions.

\subsection{Directives}

While it is not unusual to analyse certain speech act types (especially commissives and constatives) as creating speaker commitments, there seems to be a general feeling that this line of analysis doesn't extend to directives. Thus, Green (2007: 76) states that "it is hard to see how imperatives such as commands involve the undertaking of commitment." The implicature is clear: directives (or imperatives, as Green calls them) don't create speaker commitments. If this were true, it would be a major setback for my project. But I don't think it is true. If Bertha asks Alfred to walk the dog, she patently becomes committed to the goal that Alfred walk the dog. Not only is Bertha's commitment evidenced already by the very fact that she asks Alfred to walk the dog, it may well go further than that. For example, if Alfred cannot find the dog and Bertha knows where it is, then normally speaking she will be committed to share her intelligence with him.

So I take it to be plausible to suppose that by asking Alfred to walk the dog, Bertha becomes committed to the goal that Alfred walk the dog. On my analysis,

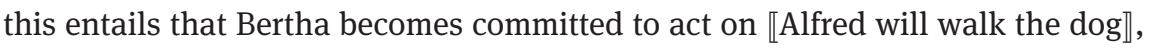
and I suspect that this consequence may be harder to accept. Surely, Bertha may 
ask Alfred to walk the dog even if she doubts that he will do so. But if that is the case, then how can it make sense for her to undertake the commitment to act on

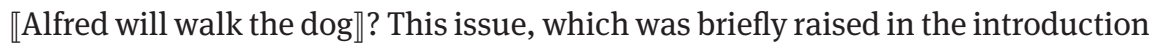
to this section, is an important one, because it bears on commitments in general.

To begin with, I assume that speakers tend only to undertake commitments that are likely to be shared by their addressees. In the case at hand this is to say that, generally speaking, Bertha will not ask Alfred to walk the dog unless she is reasonably confident that he will act accordingly. But what if confidence is lacking? What if it is common ground between Bertha and Alfred that he hates the dog and will be most reluctant to walk it? Then it may still make sense for Bertha

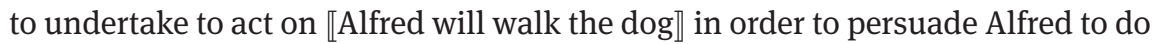
likewise. For "acting on" may imply, say, that Bertha will go on nagging Alfred for a considerable while, in which case Alfred may well give in at some point. Hence, it may be rational to undertake a commitment to act on $p$ even if it is common knowledge that $p$ is not very likely to be true.

Following Frege (1918) and many authors since, questions may be viewed as requests for information. As is well known, this isn't always right, but let's start with a case in which it is. If Bertha asks Alfred, “Are you gay?”, she doesn't merely expect him to say either yes or no: as suggested by Krifka (2015), Bertha's question causes her to become committed to act on the goal that Alfred will commit himself either to being gay or to not being gay. Schematically, this comes out as $C_{b, a} F\left(C_{a, b} p \vee C_{a, b} \neg p\right)$, where $F$ is a futurity marker often glossable as "forthwith", since questions are usually expected to be answered without undue delay.

This analysis doesn't quite capture the idea that questions are requests for information, but it goes a long way; for the most likely scenario in which Bertha commits herself to $F\left(C_{a, b} p \vee C_{a, b} \neg p\right)$ is one in which she doesn't know whether $p$ or $\neg p$, and expects Alfred to inform her which is the case. Therefore, while the proposed analysis helps to explain that questions can be requests for information, it doesn't entail that they must be. Which is what we want, for if a teacher asks a pupil, “Was Napoleon Greek?”, she doesn't expect him to enlighten her on the matter, but still expects him to commit himself one way or the other.

Despite the fact that permissives are often classified as directives (e.g. Bach and Harnish 1979; Searle and Vanderveken 1985), giving permission is unlike an order or a question in that it need not be an incentive to action, nor need it be telic in the way directives typically are. For example, if Alfred tells Bertha, "Have a seat!", it may but need not be the case that Alfred thereby becomes committed to the goal that Bertha sit down. Following Searle and Vanderveken (1985: 202) and Kissine (2013a: 109-110), I propose that the basic function of permissives is to remove a potential obstacle on the speaker's part to a potential action on the part of the addressee. Let $p$ be the proposition that Bertha will have a seat. Then 
the effect of Alfred's utterance, when interpreted in a seemingly non-committal way, is that $C_{a, b} \neg C_{a, b} \neg p$ : Alfred becomes committed to not being committed to act on $\neg p$. Which is just to say that Bertha may sit down as far as Alfred is concerned.

\subsection{Constatives}

The characteristic feature of constatives is that they bring about atelic commitments. If Agnes tells Bruce that his sister called, for example, she obviously does not commit herself to the goal that Bruce's sister called (if that is grammatical at all). Agnes's assertion constrains her actions, but doesn't steer them in any particular direction. ${ }^{5}$

Assertions have been heralded as the paradigm constatives, and have received more scholarly attention than any other type of speech act, especially from philosophers, who have touted assertion as the vehicle of choice for sharing knowledge (see Pagin (2014) for an excellent survey). On the philosophers' view, the principal purpose of assertions is to share knowledge between speakers, and several claims flow from this. First, that assertion has a privileged connection with the notion of truth. We accept some assertions as true and reject others as false. Allegedly, this practice doesn't extend to other speech acts, ${ }^{6}$ and is in line with the philosophers' view: given that knowledge entails truth, assertions are supposed to carry true information. Secondly, a speaker who conveys that he knows that such-and-such is the case is expected to be able to justify his claim when challenged to do so. Thirdly, since knowledge entails belief, assertions should carry information that the speaker believes to be true. Hence, one of the characteristic features of assertions is that they express speakers' beliefs. Fourth, if the purpose of assertion is to share knowledge, then a typical effect of the assertion that $p$ will be that $p$ becomes part of the common ground between speaker and hearer.

5 Just to be sure, to say that it is a characteristic feature of constatives that they bring about atelic commitments is not to imply that it is an essential feature of the class. As I have confessed already, I am sceptical about any form of speech act essentialism, and I am doubly sceptical about any attempt at capturing the essence of constatives in general and assertion in particular. I feel I must be explicit on this point because speech act essentialism is still rife, and especially in the literature on assertion, statements like the following are quite common: "By an account of assertion is here meant a theory of what it consists in to make an assertion. According to such accounts, there are deep properties of assertion: specifying those properties is specifying what a speaker essentially does in making an assertion [...].” (Pagin 2014: 1, no emphasis added)

6 Actually, this claim is prima facie false: promises can be true or false, warnings and oaths can be false, and so on. Of course, we might try to establish that the adjectives "true" and "false" are homonymous, but that may be hard to do without begging the question. 
Thus, the philosophers' concept of assertion is associated with a cluster of concepts that includes truth, justifiability, belief, and common ground (MacFarlane 2011; Goldberg 2015). But even if this cluster of associations seals "the philosophical significance of assertoric speech", as the subtitle of Goldberg's (2015) monograph has it, it doesn't follow that a theory of everyday communication must grant it an exclusive status as well. Be that as it may, the philosopher's view on assertion will make a convenient foil for discussing its associated concepts.

First, truth. On my account, every speech act commits the speaker to the truth of some proposition. Sharing knowledge is just one form of action coordination amongst many, and therefore epistemic concerns are less urgent for understanding communication than they are often held to be. To put it bluntly, if our first priority is to coordinate our actions, it may be more important to ensure that our commitments are the same than that they agree with the facts. If this reeks of French philosophy, I must insist that I am a great fan of knowledge, objective truth, and all that. What I question is merely the idea that this cluster of venerable concepts is of special importance to a theory of communication. Exchanging epistemically kosher information is one of the things we seek to do by way of our linguistic interactions, but more than half a century after Austin and Wittgenstein it can hardly be controversial that it is not the only thing (cf. Geurts 2018b).

Second, justifiability. While it seems correct that some uses of constatives render the speaker liable for justifying his claim, this is by no means always the case. If I assert that I'm thirsty, for example, it would be odd for you to ask, "How do you know?" On the other hand, many uses of non-constatives may well be followed up by a request for justification: ${ }^{7}$

(4) Agnes: Have you seen my hamster?

Bruce: Why do you ask?

Of course, it is true that some constatives warrant the expectation that the speaker can provide justification of a special kind, notably, evidence. But then the justificatory expectations associated with other speech act types are special, too, and as we have just seen, some assertions don't warrant such expectations at all.

Third, common ground. It is uncontroversial that constatives cause the common ground to expand. However, the same holds for non-constatives and I argue

7 As pointed out to me by Mark Jary, you might challenge my assertion that I'm thirsty: "You can't be thirsty: you just drank two litres of water.” However, if I had no idea why I felt thirsty, it would be unreasonable for you to insist on a justification. Jary also objects to example (4) on the grounds that Bruce's request for justification concerns not the question itself, but Agnes's asking it. But that depends on what we take "the question itself" to be. On Krifka's analysis (adopted in Section 3.2), it is a special kind of commitment that is justifiable, at least some of the time. 
that there are general principles that regulate such updates of the common ground. These principles are discussed in Section 4, but the basic idea is that common ground can be defined in terms of the interlocutors' commitments, and then the main effects that speech acts have on the common ground are captured by two rules that hold for all speech acts. In this respect, too, constatives are merely a special case.

Similarly, and fourthly, the observation that constatives often express beliefs generalises to the observation that speech acts quite generally license the inference that their sincerity conditions are fulfilled (to borrow Searle's 1969 terminology). For example, if Agnes tells Bruce that she is pregnant, it will normally be understood that she believes to be pregnant; if she promises Bruce to go, that she intends to go; if she orders Bruce to go, that she intends him to go; and so on. In Section 5, it is shown how, in a commitment-based framework, these inferences are derivable as conversational implicatures, again in a perfectly general and uniform way.

\subsection{Minor speech act types}

Having sampled the three major illocutionary types, we are left with a motley crew of cases, which includes greetings, condolences, apologies, verdicts, and more. Within this miscellany, two main types are often distinguished. These will be briefly discussed here, partly in order to add some further touches to the proposed account, and partly to show, pace Green (2007: 76), among others, that these speech acts, too, are commitment inducers.

First, there is a class of utterances whose main function, according to many authors, is to express psychological states, which is why Searle and Vanderveken (1985) dub them “expressives”. Bach and Harnish (1979: 51) give the following examples: "greeting expresses pleasure at meeting or seeing someone, thanking expresses gratitude for having received something, apologizing expresses regret for having harmed or bothered the hearer." On reflection, it is doubtful that greetings generally express pleasure, and it may also be doubted that expressing a psychological state is the main purpose of any of these speech acts. It seems more plausible, for example, that the main purpose of greetings is to open and close bouts of social interaction.

However, we will let these candidate issues lie and focus on what is the key point for our current purposes: even if it is correct that the main function of these and other speech acts is to express psychological states, then that doesn't preclude a commitment-based analysis. On the contrary, it is entirely natural to interpret (or reinterpret) “expressing” in terms of commitment: thanking commits 
the speaker to being grateful, apologising commits her to being regretful, and so on. This analysis brings expressives in line with the major speech acts, all of which create commitments of the form $C_{a, b} p$. The distinctive feature of expressive speech acts is just that $p$ attributes a psychological state to $a$, a feature they share with first-person attitude reports, like:

(5) I believe there is nutmeg in the pudding.

Come to think of it, this analysis suggests that expressive speech acts are a subclass of constatives, namely, those that attribute a psychological state to the speaker. This suggestion is strengthened by the observation that, attitudes aside,

(5) and (6) seem to share the same semantic blueprint:

(6) I'm sorry there is nutmeg in the pudding.

In stark contrast to expressives, the psychology of the speaker seems wholly irrelevant to the conventional speech acts that Austin (1962) was preoccupied with:

(7) I find the defendant guilty of armed robbery.

(8) I christen this ship the USS Stormy Daniels.

(9) I hereby declare war on the Balearics.

No matter whether the judge believes the defendant to be guilty or not, by uttering (7) a verdict will have been pronounced in either case; likewise, mutatis mutandis, for (8) and (9), when uttered by the incumbent US president, for example. In none of these cases do the felicitousness and success of the speech act depend on the speaker's beliefs, intentions, or any other psychological states. However, it is clear that each of these speech acts causes the speaker to become committed to act on the proposition expressed. A judge who utters (7) henceforth

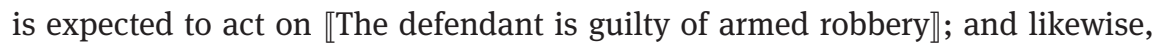
mutatis mutandis, for (8) and (9).

\subsection{Commitments and communicative intentions}

In his landmark 1964 paper, Strawson proposed a dichotomy between Austinian speech acts involving "rule- or convention-governed practices and procedures of which they essentially form parts" (p.457), on the one hand, and speech acts that are not conventional in this sense, on the other. On Strawson's account, a non-conventional speech act essentially involves what has come to be called a "communicative intention", which is an intention to produce in the hearer a belief or other attitude by means of her recognition of this very intention. (This is how Grice's 1957 concept of “non-natural meaning” entered the speech act literature, albeit under a different name.) For example, if Agnes informs Bruce that tea is 
ready, then she intends him to form the belief that tea is ready because he grasps her intention.

Strawson's dichotomy has been highly influential, and is respected even by theories like Kissine's (2013a) that adopt a non-Gricean analysis of nonconventional speech acts. Therefore, it is of some interest to note that the theory proposed here offers a unified account of conventional and non-conventional speech acts. For, as observed above, there is no reason to exempt conventional speech acts from the general principle that a speech act causes a commitment for the speaker. This is not to reject Strawson's dichotomy altogether, but it is to say that it is not fundamental to my account the way it is to Bach and Harnish's (1979) or Kissine's (2013a), among many others.

Although dissenting opinions aren't rare, the mainstream doctrine across disciplines is that human communication essentially involves expressing and grasping communicative intentions. I am with the dissenters. Commitments can do most of the theoretical work that communicative intentions are held to do, and they can do a great deal more. As discussed three paragraphs ago, whereas intention-based theories cannot accommodate conventional speech acts, exemplified by (12)-(14), and therefore write them off as non-communicative uses of language (e.g. Bach and Harnish 1979), a commitment-based analysis applies to conventional and non-conventional speech acts alike. Further proof of the explanatory power of commitments will be given in the following sections.

In addition to these explanatory virtues, there is one consideration that is relevant in the bigger scheme of things. Intention-based communication is essentially a matter of conveying communicative intentions: it is the speaker's job to express a communicative intention and the hearer's to grasp it. Hence, in order to be successful, every speech act requires that the speaker knows beforehand, and that the hearer comes to know, what the speaker's communicative intention is. Not so with commitments. Commitments are interpersonal relationships that are established in the wake of our social activities, and it is entirely possible to engage in the game of sharing and acting on commitments without knowing one's commitments or others', and indeed without knowing what commitments are. This is an important reason to believe that the prospects for commitment-based theories of the ontogeny and phylogeny of human communication are a lot rosier than for intention-based accounts.

\section{Common ground}

Having thus far studied speech acts from the speaker's standpoint, from now on the focus will be on interpersonal aspects of communication, starting with 
common ground. Since its introduction by Grice in his William James lectures of 1967, common ground has become one of the key notions in pragmatics, figuring prominently in theories of convention (Lewis 1969; Geurts 2018a), conversational implicatures (Grice 1975; Geurts 2010), reference (Clark and Marshall 1981), presupposition (Stalnaker 1973, 2002), speech acts (Bach and Harnish 1979), vagueness (Lewis 1979), and many other pragmatic phenomena. By definition, the common ground contains information that is "in the open", and this openness is standardly characterised in terms of mutual (or common) knowledge or belief. The fingerprint of these mutualistic notions is their iterative structure, illustrated here with mutual belief. Using $B_{x} p$ as a shorthand for " $x$ believes $p$ ", it is mutual belief between $a$ and $b$ that $p$ iff:

$$
\begin{gathered}
B_{a} p \text { and } B_{b} p, \\
B_{a} B_{b} p \text { and } B_{b} B_{a} p, \\
B_{a} B_{b} B_{a} p \text { and } B_{b} B_{a} B_{b} p,
\end{gathered}
$$

This endless cascade has prompted the strangely persistent myth that common ground, thus characterised, is impossible to achieve in real life, and that therefore the concept is best abandoned altogether. (An outstanding source of this myth, among others, was Sperber and Wilson 1986.) However, for reasons already explained by Lewis, this objection is unfounded. The critical point is that the iterative structure of common ground "is a chain of implications, not of steps in anyone's actual reasoning. Therefore there is nothing improper about its infinite length.” (Lewis 1969: 53)

Although Lewis's reply settles the matter, it does nothing to explain how common ground is achieved. It is widely agreed that there are two main ways. One is that there are many types of situations, or "bases" as Lewis calls them, that create common ground (Clark 1992, 1996). People interacting with each other will soon find out whether they share the same language, the same social background, the same hobbies, and so on, and any of these commonalities will serve as a basis for common ground. The second way of reaching common ground is by means of communication. For example, an utterance of "Clyde snores" may be seen, following Stalnaker (1978), as a proposal to augment the common ground with the information that Clyde snores, and as a rule this information will become part of the common ground, unless the hearer objects. It is this way of building common ground that we will be concerned with here.

In the current framework, it is natural to analyse common ground in terms of mutual commitment, which is defined as follows: $a$ and $b$ are mutually committed to act on $p$ iff: 


$$
\begin{aligned}
C_{a, b} p & \text { and } C_{b, a} p, \\
C_{a, b} C_{b, a} p & \text { and } C_{b, a} C_{a, b} p, \\
C_{a, b} C_{b, a} C_{a, b} p & \text { and } C_{b, a} C_{a, b} C_{b, a} p,
\end{aligned}
$$

Mutual commitment has the same iterative structure as mutual belief and mutual knowledge, and by and large it can do the same theoretical work as its doxastic and epistemic cousins. But there are very substantial differences, too. Whereas on the received view, the common ground is an information pool that supports interactions between its owners, construing it as a set of mutual commitments entails that common ground is a normative construct, which not only supports but also constrains actions, and thus helps to coordinate them. Moreover, mutual commitment is a social concept, not a psychological one, and it doesn't entail belief, let alone mutual belief. Henceforth, I will use the terms "common ground" and "mutual commitment" interchangeably.

Having shown how common ground can be represented by means of commitments, let us now consider how communication changes the common ground. We start with the observation that every speech act type is associated with a normal response: questions tend to get answered, requests tend to be granted, assertions tend to be accepted, and so on. Of course, these normal responses aren't always obtained, and sometimes not even expected; but most of the time they are expected and obtained. One of the strong points of the theory on offer is that it allows us to formulate a simple rule that captures all these cases at once. Let's say that $a$ and $b$ share a commitment to act on $p$ iff $C_{a, b} p$ and $C_{b, a} p$. Then the rule is that commitments are normally shared:

Commitment sharing: If $C_{a, b} p$, then ceteris paribus $C_{b, a} p$.

The sharing rule entails that, whenever $a$ performs a speech act that causes $C_{a, b} p$, then ceteris paribus $C_{b, a} p$ will come to hold, too. Thus we obtain the following predictions:

Ceteris paribus:

(10) If Agnes tells Bruce, "Clyde is mowing the lawn", then Bruce becomes

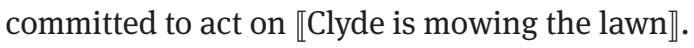

(11) If Agnes promises Bruce, "I'll mow the lawn", then Bruce becomes committed to act on $\llbracket$ Agnes will mow the lawn $\rrbracket$.

(12) If Bruce asks Agnes, “Can you pass the gravy, please?”, then Agnes becomes

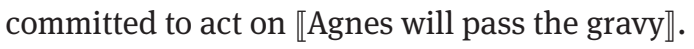

(13) If Bruce asks Agnes, “Is Donald gay?”, then Agnes becomes committed to commit herself to act either on $\llbracket$ Donald is gay or on $\llbracket$ Donald is not gay 
Note that a shared commitment may be telic for one party but not for the other. (11) is a case in point.

What is the status of the sharing rule? To begin with, it seems correct from a descriptive point of view: it does seem to be the case that, normally speaking, statements are accepted as true, requests are granted, questions answered, and so on. The reason why this pattern holds is not that speech acts have a mysteriously compelling force, but because in general interlocutors are cooperative: speakers seek to ask questions that will be answered, make statements that will be accepted, and so on, and hearers will respond accordingly, more often than not. ${ }^{8}$ If this explanation is correct, the sharing rule doesn't cause the interactive pattern it captures, but nevertheless, if sharing is the normal case, as the rule states, then speakers and hearers may come to treat it as normative to some degree: we answer questions not only because we like to help, or because we're accustomed to do so, but also because we are supposed to do so. In the same way, the sharing rule may also become a motivating factor in the development of communicative skills.

Still, an addressee may decline to share a commitment made by the speaker. Bruce tells Agnes that Napoleon was Greek, but she refuses to believe him; or Agnes promises Bruce to be at the station when he arrives, but he tells her that she is not going to make it on time. In such cases, the speaker's commitment is not necessarily voided, though it may become pointless. Even if Agnes refuses to accept Bruce's statement as true, he may decide to stick to his commitment, and try to convince her that he is right. But when Bruce expresses doubts about Agnes's promise, he cannot expect her to stick to her commitment, though she might. In short, it depends on the case. Commitment sharing is the norm, and unshared commitments undercut the main purpose of communication, but they do not defeat it altogether. Even if Bruce fails to convince Agnes, they may agree to disagree, which is a form of coordination, too.

Before the addressee can act on the speaker's commitment, he must first accept that a commitment was made in the first place. There are many ways in which this precondition can fail to hold: the addressee may be out of earshot, deaf, unconscious, suffer from receptive aphasia, and so on. Briefly, a commitment requires “uptake”, as Austin (1962) called it (cf. Clark 1996, chapter 8, Kibble 2006a). I take this to mean that $a$ 's commitment to act on $p$ doesn't hold unless $b$ commits herself to act on the proposition that $a$ is thus committed. Acceptance may be signalled (“Hmm”, “Okay”, ...), but it may also be merely implied by the

8 This is not the same thing as cooperativity in Grice's (1975) sense of the word. Gricean cooperativity requires a common goal, and though it may be true that when I answer your question, for example, your goal thereby becomes a common goal (or, in the jargon of this paper, a mutual telic commitment), it is not generally the case that questions address common goals. 
hearer's response (an appropriate answer implies acceptance of the commitment associated with the question, for example), and even in the absence of overt clues acceptance is usually taken for granted.

Although, in the speech act literature, the responsibility for acceptance is supposed to lie with the addressee alone, it seems reasonable to hold the speaker responsible, too. In fact, it is hard to see how a speaker could commit herself to act on $p$ without committing herself to being committed to act on $p$. Therefore, acceptance must be shared between speaker and hearer:

Acceptance: $C_{a, b} p$ entails $C_{a, b} C_{a, b} p$ and $C_{b, a} C_{a, b} p$.

It must be stressed that, whereas commitment sharing is merely a default, Acceptance is proposed as a prerequisite for commitment. Commitment is a relation between two consenting parties, and there is no commitment unless it is accepted by both.

It immediately follows from the definition of Acceptance that a speaker cannot have a commitment without it being common ground that he is thus committed. That is to say, $C_{a, b} p$ entails that

$$
\begin{gathered}
C_{a, b} C_{a, b} p \text { and } C_{b, a} C_{a, b} p, \\
C_{a, b} C_{b, a} C_{a, b} p \text { and } C_{b, a} C_{a, b} C_{a, b} p, \\
C_{a, b} C_{b, a} C_{a, b} C_{a, b} p \text { and } C_{b, a} C_{a, b} C_{b, a} C_{a, b} p,
\end{gathered}
$$

Furthermore, it follows that shared commitments are eo ipso common ground: if $C_{a, b} p$ and $C_{b, a} p$, then it must be the case that there is a mutual commitment between $a$ and $b$ to act on $p$. Hence, commitments are twice grounded in concordant commitments between interlocutors (cf. Clark 1992, 1996, Geurts 2018a).

To sum up, this analysis of common ground captures the intuitive idea that commitments between speakers are "in the open", and it does so on two levels. First, commitments cannot exist without it being common ground that they exist: Agnes's promise to Bruce doesn't commit her to anything unless it is common ground between her and Bruce that she has undertaken a commitment. Second, a shared commitment is necessarily a mutual commitment: if Agnes and Bruce agree to do the dishes together, they don't have a shared commitment unless it is common ground between them that they will do the dishes together.

By defining common ground as mutual commitment we don't lose any of the advantages of standard definitions in terms of knowledge or belief. For example, analyses of presupposition, definite reference, and convention are accommodated just as easily in the present framework as in standard ones. This is important, 
because, as noted at the beginning of this section, common ground is widely agreed to be fundamental to communication, and a key factor in a wide range of pragmatic phenomena. The distinctive feature of mutual commitment is that it entails neither belief nor knowledge. This implies that Agnes and Bruce may agree that Napoleon was Greek even though it is mutual belief between them that he was French. I welcome this consequence, not only because it enables us to treat telic and atelic commitments on a par, but also because it opens the door to analyses of pretence, fiction, and hypothesising that treat these forms of discourse as continuous with "ordinary" discourse (cf. Geurts 2017). Nevertheless, it is obviously true that in much of our everyday interactions common ground does entail belief. In the upcoming section it will be explained why that is the case.

\section{Conversational implicature}

From the late 1950s onwards, Grice launched several concepts that have been instrumental in defining the field of pragmatics. Two of these were discussed in the foregoing: communicative intention, which derives from Grice's "nonnatural meaning" (Section 3.5), and common ground (Section 4). This section is about conversational implicature, which is yet another key pragmatic concept contributed by Grice. My objective in the following pages is to show how conversational implicatures may be analysed in a commitment-based framework. This will involve some rethinking, because Gricean pragmatics is cast in psychological terms.

Grice (1975) sees communication as a collaborative effort. A discourse is a joint project aimed at achieving one or several common goals. Common goals are part of the common ground; in the jargon of this paper, they are mutual commitments of the telic variety. Given that communication is a joint project, it is natural to suppose that an utterance $p$ will normally be interpreted in the light of the current discourse goals, on the assumption that $p$ was designed by the speaker to further these goals. In other words, hearers will assume that speakers abide by Grice's “Cooperative Principle”, which enjoins the speaker to tailor his utterances to the discourse goals (1975/1989: 26). The Cooperative Principle is Grice's "overarching principle” for a theory of cooperative communication. Grice presents his theory as a collection of more specific "maxims", loosely arranged into four rubrics (1975/1989: 26-27):

- Quality: Try to make your contribution one that is true:

1. Do not say what you believe to be false.

2. Do not say that for which you lack adequate evidence. 
- Quantity:

1. Make your contribution as informative as is required (for the current purposes of the exchange).

2. Do not make your contribution more informative than is required.

- Relation: Be relevant.

- Manner: Be perspicuous:

1. Avoid obscurity of expression.

2. Avoid ambiguity.

3. Be brief (avoid unnecessary prolixity).

4. Be orderly.

Note that, for the most part, the Gricean maxims are formulated in non-psychological terms. The only exception is the first Quality maxim, which refers to the speaker's beliefs. This maxim will soon receive due attention, but first we turn to the pragmatic inferences licensed by the maxims: conversational implicatures, or "implicatures" for short. An implicature is "what has to be supposed in order to preserve the supposition that the Cooperative Principle is being observed" (Grice 1975/1989: 39-40). Implicatures are derived on the basis of what the speaker says, the common ground, and the assumption that the speaker is being cooperative. Grice provides a general schema for deriving implicatures, which is replete with psychological terminology. According to this schema, a hearer is entitled to reason as follows:

[The speaker] has said that $p$; there is no reason to suppose that he is not observing the maxims, or at least the Cooperative Principle; he could not be doing this unless he thought that $q$; he knows (and knows that I know that he knows) that I can see that the supposition that he thinks that $q$ is required; he has done nothing to stop me thinking that $q$; he intends me to think, or is at least willing to allow me to think, that $q$; and so he has implicated that $q$. (Grice 1975/1989: 31)

Based on this schema, it may seem natural to suppose that the Gricean concept of implicature itself is irredeemably psychological. However, that is not the case, for we can recast Grice's schema in non-psychological terms, along the following lines:

It is common ground that:

$i$. the speaker has said that $p$;

ii. he observes the maxims;

iii. he could not be doing this unless he was committed to $q$;

$i v$. he has done nothing to prevent $q$ from becoming common ground;

$v$. he is committed to the goal that $q$ become common ground.

And so he has implicated that $q$. 
Two caveats are in order here. First, in my version of the Gricean schema I have cut down on the characteristic hedging of the original version. Second, since the point of this exercise is merely to show that Grice's reasoning can be replicated in terms of commitment, the quality of the reasoning is no better than in the original. That quality is somewhat debatable, though it must be stressed that Grice was aiming for plausibility rather than proof: conversational implicatures are inferences to the best explanation, and therefore not expected to be deductively valid (Geurts 2010: 36-39, 73-74).

In order to bolster the claim that Gricean pragmatics can be embedded in a commitment-based framework, we need a Gricean theory that achieves at least a modest standard of explicitness and rigour. To date, there are no general theories of implicature that meet this requirement. However, there are partial theories that go some of the way. The most prominent case in point is the Gricean analysis of quantity implicatures, the first explicit version of which was given by Soames (1982) (see Geurts 2010, chapter 2, for discussion). This analysis is standardly formulated in terms of intentions and beliefs, but it is easily recast in terms of commitments, as I will show with the following example. Alice reports to Brian that she has caught Clyde handling her purse, whereupon he fled the scene while she checked her purse to find that:

(14) Clyde took some of the money.

Alice's utterance is likely to imply that Clyde didn't steal all the money. This inference can be accounted for as an implicature based on the first Quantity maxim, along the following lines:

It is common ground that:

$i$. Instead of saying (14), Alice could have made a stronger statement:

(15) Clyde took all the money.

This raises the question why Alice uttered (14) rather than (15).

ii. The most likely explanation is that Alice doesn't have sufficient evidence to be committed to act on $\llbracket(15) \rrbracket$.

[weak implicature]

iii. Alice has sufficient evidence to be committed to act on either $\llbracket(15) \rrbracket$ or $\llbracket \neg(15) \rrbracket$.

iv. Between them, (ii) and (iii) entail that Alice has sufficient evidence to be committed to act on $\llbracket \neg(15) \rrbracket$.

v. Therefore, Alice is committed to act on $\llbracket \neg(15) \rrbracket$. [strong implicature]

And so Alice has implicated that Clyde didn't take all the money.

This derivation follows the standard recipe, but sans beliefs or intentions. Two glosses may be helpful here. First, (iii) is implied by the context: given that Alice checked her purse, she either has evidence that Clyde took all her money or she 
has evidence that he took only some of it. If this assumption didn't hold, the conclusion that Clyde didn't take all the money would not follow, though the weaker implicature in (ii) might still hold. Secondly, $(v)$ is entailed by (iv) on the premiss that, if it is common ground that $x$ has sufficient evidence to be committed to the truth of $p$, then $x$ is committed to the truth of $p$. So here it is critical that the protasis is common ground.

We now return to the first Quality maxim, which enjoins the speaker not to say what she believes to be false. This is the only maxim that refers to a psychological state, and I can't see how it could be reformulated in terms of commitment, understood as a social relation. However, this is not to say that Quality ${ }_{1}$ cannot be reformulated in terms of commitment at all. As briefly discussed in Section 2, we undertake commitments so as to coordinate our actions, and action coordination takes place on more than one level. The bulk of this paper deals with action coordination between people, because my working hypothesis is that this is the key level for understanding communication. However, in a broader perspective, action coordination for oneself is no less important than coordination with others, and just as we make social commitments to others so as to coordinate our actions with theirs, we make private commitments to ourselves to coordinate our own actions (cf. Clark 2006, Geurts 2018b). In the remainder of this section, I will

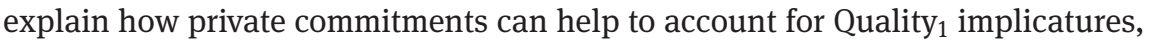
and much more.

I have argued elsewhere that private commitments are essentially involved in self talk (Geurts 2018b). People do not only talk to others; they also talk to themselves, and self talk is associated with a variety of higher mental functions, including reasoning, problem solving, planning, attention, and motivation (Winsler 2009, Vicente and Martinez Manrique 2011). As long as we adopt the received view that defines communication as information exchange, self talk is an anomaly, because it is hard to see the point of exchanging information with oneself. However, if communication is viewed as a way of negotiating commitments between speaker and hearer, then communication may be useful even when speaker and hearer coincide. For, whereas information exchange with oneself is futile, making commitments to oneself is not.

To illustrate, suppose that Brian promises Alice and himself to mow the lawn. Brian's promise to Alice entitles her to plan her activities on the premiss that Brian will mow the lawn, so she can take it as given that she will not have to do it, that Brian will be out of the house for at least an hour, and so on. Likewise, Brian's promise to himself entitles him to make his plans on the premiss that he will mow the lawn, so he will not have to ask Alice to do it, he will be busy for at least an hour, and so on. Thus social and private commitments serve the same purpose. If $C_{a, b} p$, $a$ 's commitment helps $a$ and $b$ to coordinate their activities. The difference 
between social and private commitments is mainly that $a \neq b$ in the former case, while $a=b$ in the latter.

It is a recurrent theme in the philosophy of language that commitments are closely linked to, if not equatable with, beliefs and/or intentions. ${ }^{9}$ Thus Brandom (1997) distinguishes between

[...] doxastic commitments, which do much of the theoretical work usually done by notions of belief, and practical commitments (commitments to do something), which do much of the theoretical work usually done by notions of intention. (p.199)

Although Brandom's practical/doxastic distinction doesn't coincide with my telic/atelic distinction, the two are related, and we can transpose Brandom's statement into the present framework as follows: private telic commitments are intentions, and private atelic commitments are beliefs. If Brian is privately com-

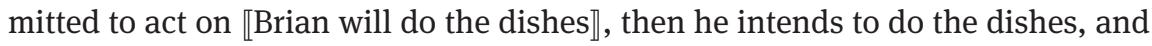
if he is privately committed to act on $\llbracket$ Napoleon was Greek》, then he believes that Napoleon was Greek.

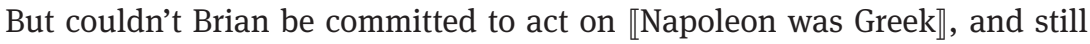
believe that he was French? Not unless his commitment was merely social, halfhearted, or both. While our social commitments primarily constrain our public actions, whole-hearted private commitments constrain our actions across the board, including the ones we perform for ourselves. So only if Brian's private conduct respects the premiss that Napoleon was Greek is he privately committed that Napoleon was Greek. But in that case he believes that Napoleon was Greek. The same, mutatis mutandis, for private telic commitments and intentions.

The claim that private commitments are beliefs and intentions does not entail that beliefs and intentions are subtypes of private commitments. Our everyday notion of belief has several aspects, only one of which can be equated with the notion of private atelic commitment. One aspect is dispositional: we attribute beliefs on the basis of what a person tends to do. Another aspect is normative: we attribute beliefs on the basis of what a person is supposed to do. Since there is a positive correlation between what we are supposed and disposed to do, these two aspects of belief are closely related. A third aspect is properly mentalistic: we localise beliefs in their owners, and treat them as the underlying causes of their actions. Other mental-state concepts, like intention, may be broken down along the same lines. ${ }^{10}$

9 See Segerberg (1984) and Bratman (1987) on the commitment/intention nexus, Jacquette (2013) on belief, and Brandom (1994) on both.

10 It is widely accepted that mental-state concepts are not always unitary, and while there is no consensus on what the relevant parts or aspects are, it is a common idea that beliefs and 
I believe that dispositions and norms are the workhorses of our folk psychology, and that we interpret, explain, and predict the bulk of people's behaviour (including our own) in terms of what they are supposed and/or disposed to do; the whereabouts of a mental state are seldom of interest. This holds in particular for social interaction and more in particular for communication. However, this is as it may be, for the main point is that belief and intention are composite concepts, and that only their normative aspects can be equated with private commitments. With this proviso, let's suppose that private commitments are intentions (if telic) and beliefs (if not).

Although from a communicative point of view, it is perfectly possible to undertake conflicting commitments, it will be clear that, generally speaking, one shouldn't do so, and is expected not to do so. If Alice accepts Brian's marriage proposal as well as Clyde's, she may have successfully undertaken conflicting commitments, but nevertheless her conduct is dubious, because at least one of her two bids for action coordination is bound to come up empty. Hence, being rational and responsible agents, we expect one another to honour the following maxim:

Integrity: If $C_{a, b} p$ then $\neg C_{a, c} \neg p$.

In prose, the Integrity maxim enjoins speakers to avoid conflicting commitments. Having promised to marry Brian as well as Clyde, Alice's commitments violate this maxim, because the propositions that she will marry Brian and Clyde, respectively, cannot be true together.

While the Integrity maxim holds for any $a, b$, and $c$, it has two submaxims that are of special interest. First, if $b=c$, we have:

Consistency: If $C_{a, b} p$ then $\neg C_{a, b} \neg p$.

As observed in Section 2, this is not merely a maxim, but a prerequisite for commitment: making contradictory commitments to one and the same person is no better than making no commitment at all, and possibly worse. The second submaxim follows from Integrity if $a=c$ :

Sincerity: If $C_{a, b} p$ then $\neg C_{a, a} \neg p .^{11}$

Whenever $a \neq b$, this maxim yokes $a$ 's private commitments, i.e. her beliefs and intentions, to her social commitments. To illustrate the implications of this sub-

intentions have a normative aspect (see, e.g. Dennett 1987, Frankish 2004, Apperly 2011, Zawidzki 2013).

11 As it is used here, "sincerity" is a term of art, which means just what it is defined to mean. For reasons given by Ridge (2006), I wouldn't want to claim that this definition fully captures our pre-theoretical notion of sincerity, although it is not such a bad approximation either. 
maxim, suppose it is common ground between Alice and Brian that she is sincere. Then all of the following hold:

(16) If Alice tells Brian she is pregnant, she doesn't believe she is not pregnant.

(17) If Alice promises Brian to go, she doesn't intend not to go.

(18) If Alice orders Brian to go, she doesn't intend him not to go.

If Alice believes that she is not pregnant, then $C_{a, a} \neg(a$ is pregnant), and it follows from the Sincerity maxim that she musn't act in such a way that she undertakes $C_{a, b}(a$ is pregnant). That is to say, if she believes she is not pregnant, she shouldn't tell Brian that she is, and therefore, if she tells Brian that she is pregnant, she implicates that she doesn't believe she is not pregnant. (17) and (18) are derivable in much the same way.

While the implicatures in (16)-(18) are correct as far as they go, they are relatively weak, and often enough addressees are entitled to make stronger inferences:

(19) If Alice tells Brian she is pregnant, she believes she is pregnant.

(20) If Alice promises Brian to go, she intends to go

(21) If Alice orders Brian to go, she intends him to go.

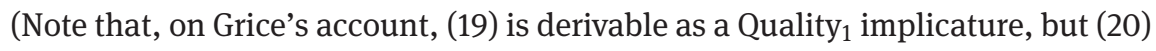
and (21) are not.) The general situation is as follows. Courtesy of the Sincerity maxim, we can derive an implicature of the form $\neg C_{a, a} \neg p$, which is correct but not always as strong as what we would like to have, which is an implicature of the form $C_{a, a} p$. This is reminiscent of the distinction between weak and

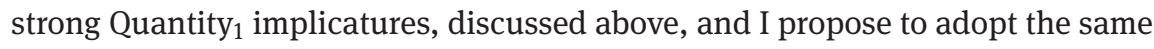
style of analysis in this case, too. The idea is that $\neg C_{a, a} \neg p$ is strengthened to $C_{a, a} p$ whenever it is common ground that $C_{a, a} p \vee C_{a, a} \neg p$. To see how this solution applies to the examples at hand, consider (16) again. Suppose Alice either believes that she is pregnant or believes that she is not pregnant. Surely, this premiss holds for most women most of the time, and perhaps it is even more likely to be true in the kind of situation that prompts a woman to assert that she is pregnant. Anyway, whatever the odds, if this premiss holds, it is of the form $C_{a, a} p$ $\vee C_{a, a} \neg p$. Due to the Sincerity assumption, Alice's statement causes the commitment $\neg C_{a, a} \neg p$, which rules out the second disjunct, and thus it follows that $C_{a, a} p$ : Alice believes that she is pregnant. On parallel assumptions, (20) and (21) are derivable from (17) and (18), respectively.

According to this analysis, the strengthening of sincerity implicatures depends on the context, but that dependence does not make it as tenuous as one might think. To see why, note that the auxiliary premiss $C_{a, a} p \vee C_{a, a} \neg p$ merely eliminates the possibility that $a$ hasn't made up her mind as to whether she is privately committed to $p$ or to $\neg p$. This much should be plausible enough in many 
contexts, but especially in such contexts that license sincerity implicatures in the first place, where $a$ just undertook a social commitment to $p$.

To conclude, the proposed account predicts that, courtesy of the Sincerity maxim, there will be a general trend for an utterance causing $C_{a, b} p$ to also cause $\neg C_{a, a} \neg p$ and $C_{a, a} p$ as knock-on effects, so to speak. This captures Quality inferences, and many more besides, because the analysis generalises across speech act types. Whereas Grice's Quality maxims are tailored to assertions, the Integrity maxim (of which Sincerity is a special case) uniformly applies to all speech acts. The range of strong implicatures licensed by the Sincerity maxim roughly coincides with the range of Searle's "sincerity conditions" (Searle 1969; Searle and Vanderveken 1985). However, whereas on Searle's analysis sincerity conditions have to be stipulated for each speech act type individually, the analysis proposed here derives Sincerity implicatures from the social commitments associated with speech acts, and does so in a perfectly regular way. (For further discussion of sincerity, see Falkenberg 1997, Ridge 2006, and Lauer 2013.)

\section{Conclusion}

I take it that the first order of business for any theory of linguistic communication is to explain what speech acts are, how they interact with the common ground, and how they give rise to Gricean inferences. The orthodox way of dealing with these requirements is to start from the general assumption that the principal purpose of communication is the exchange of information, specifically information about the speakers' mental states, and more specifically about their communicative intentions. Although it is by no means unprecedented, the approach I have taken in this paper is heterodox. It starts from the assumption that the principal purpose of communication is to share commitments that serve to facilitate action coordination. In the foregoing I have shown how speech acts can be uniformly analysed as commitment-sharing devices; how common ground can be defined in terms of commitments, which are updated by speech acts in accordance with simple and quite general principles; how conversational implicatures can be derived in a commitment-based framework; and how beliefs and intentions can be viewed as private commitments, which are key elements in my analyses of self talk and sincerity implicatures.

Needless to say, the general framework outlined here needs further development in all sorts of ways, but it shouldn't be hard to see that it will easily accommodate extant analyses of a wide variety of pragmatic phenomena, including presupposition, reference, convention, and figurative meaning. In many cases, this is true even if the analyses in question were originally formulated in mentalistic frameworks. Which is to say that, when viewed topic by topic, the 
shift in perspective from the psychological to the social is less consequential than it might seem at first.

It bears emphasising that adopting a commitment-based approach does not require that we give up on the idea that speech acts express mental states. On the contrary, even if social commitments are now in the driver's seat, mental states retain a very respectable position in the back seat, and it could hardly be otherwise. It would be futile to deny that the main job of some speech acts is to express belief ("I believe this is oregano") or joy ("Hurrah!"), for example, and the commitment-based analysis of speech acts allows for this, as it should. But more importantly, we have seen how private commitments, i.e. beliefs and intentions, are derivable from social commitments in a principled way, while still allowing for cases in which sincerity inferences are not observed, like the conventional speech acts discussed in Section 3.4. Therefore, the commitment-based account is consistent with the possibility that, much if not most of the time, speech acts express mental states, even if mental-state attribution is less central to the current account than to the received view, and not a prerequisite for communication. Thus it is readily explained how children can have a basic understanding of promising, say, without understanding that promises express intentions.

Speaking of children, we saw in the introduction that by making mentalstate attribution a sine qua non for linguistic communication, the received view makes it hard, if not impossible, to construct ontogenetic or phylogenetic models without breakthrough events, like when a toddler is suddenly struck by the realisation that the utterance, "I'll buy you an ice cream", expresses the parent's intention to let the child believe, due to its understanding of that very intention, that he or she intends to provide the child with an ice cream.

On the view expounded in this paper, children must find their way into a normative practice of sharing commitments and planning their actions accordingly. They are aided in the process by the statistical regularities created by this very practice. Promising an ice cream, for example, is a social practice that creates significant correlations between speech patterns and subsequent patterns of behaviour. Once attuned to these correlations, the child still has to proceed from what people are disposed to do to what they are supposed to do. But that transition can be piecemeal and gradual, and may therefore be accounted for without breakthrough events of any kind.

Acknowledgment: I've had a lot of help with this one. Thanks to Philippe De Brabanter, Vitaliy Dolgorukov, Hans-Martin Gärtner, Mark Jary, Mikhail Kissine, John Michael, Tim Reuten, Marat Shardimgaliev, Mandy Simons, Martina Valković, Till Vierkant, Huub Vromen, and an anonymous reviewer for Theoretical linguistics. Research for this paper was supported by the Russian Academic Excellence Project 5-100. 


\section{References}

Anscombe, G. 1957. Intention. Oxford: Blackwell.

Apperly, I. A. 2011. Mindreaders: The cognitive basis of "theory of mind". Hove: Psychology Press.

Austin, J. L. 1962. How to do things with words. Oxford: Oxford University Press.

Bach, K. \& R. M. Harnish. 1979. Linguistic communication and speech acts. Cambridge, MA: MIT Press.

Beyssade, C. \& J.-M. Marandin. 2009. Commitment: Une attitude dialogique. Langue Française 162. 89-107.

Brandom, R. 1994. Making it explicit. Cambridge, MA: Harvard University Press.

Brandom, R. 1997. Replies. Philosophy and Phenomenological Research 57. 189-204.

Bratman, M. E. 1987. Intention, plans, and practical reason. Cambridge, MA: Harvard University Press.

Clark, H. H. 1992. Arenas of language use. Chicago: University of Chicago Press.

Clark, H. H. 1996. Using language. Cambridge: Cambridge University Press.

Clark, H. H. 2006. Social actions, social commitments. In N. Enfield \& S. C. Levinson (eds.), Roots of human sociality: Culture, cognition and interaction, pp. 126-150. Oxford: Berg.

Clark, H. H. \& C. Marshall. 1981. Definite reference and mutual knowledge. In A. Joshi, B. L. Webber \& I. Sag (eds.), Elements of discourse understanding, pp. 10-63. Cambridge: Cambridge University Press.

De Brabanter, P. \& P. Dendale. 2008. Commitment: the term and the notions. In P. De Brabanter \& P. Dendale (eds.), Commitment, pp. 1-14. Amsterdam: Benjamins.

Dennett, D. C. 1987. The intentional stance. Cambridge, MA: MIT Press.

Falkenberg, G. 1997. Searle on sincerity. In A. Burkhardt (ed.), Speech acts, meaning and intentions: critical approaches to the philosophy of John R. Searle, pp. 129-146. Berlin: De Gruyter.

Frankish, K. 2004. Mind and supermind. Cambridge: Cambridge University Press.

Frege, G. 1918. Der Gedanke. Beiträge zur Philosophie des deutschen Idealismus 1. 58-77.

Gazdar, G. 1981. Speech act assignment. In A. Joshi, B. L. Webber \& I. Sag (eds.), Elements of discourse understanding, pp. 64-83. Cambridge: Cambridge University Press.

Geurts, B. 2010. Quantity implicatures. Cambridge: Cambridge University Press.

Geurts, B. 2017. Fictional commitments. Theoretical Linguistics 43. 53-60.

Geurts, B. 2018a. Convention and common ground. Mind and Language 33. 115-129.

Geurts, B. 2018b. Making sense of self talk. Review of Philosophy and Psychology 9. 271-285.

Goldberg, S. C. 2015. Assertion: The philosophical significance of assertoric speech. New York: Oxford University Press.

Green, M. S. 2007. Self-expression. Oxford: Oxford University Press.

Grice, H. P. 1957. Meaning. Philosophical Review 66. 377-388. Reprinted in Grice (1989).

Grice, P. 1975. Logic and conversation. In P. Cole \& J. Morgan (eds.), Speech acts (Syntax and semantics 3), pp. 41-58. New York: Academic Press. Reprinted in Grice (1989).

Grice, P. 1989. Studies in the way of words. Cambridge, MA: Harvard University Press. Hamblin, C. L. 1971. Mathematical models of dialogue. Theoria 37. 130-155.

Jacquette, D. 2013. Belief state intensity. In N. Nottelmann (ed.), New essays on belief: Constitution, content, and structure, pp. 209-229. Houndmills, Basingstoke: Palgrave Macmillan.

Kibble, R. 2006a. Reasoning about propositional commitments in dialogue. Research on Language and Computation 4. 179-202. 
Kibble, R. 2006b. Speech acts, commitment and multi-agent communication. Computational and Mathematical Organization Theory 12. 127-145.

Kissine, M. 2013a. From utterances to speech acts. Cambridge: Cambridge University Press.

Kissine, M. 2013b. Speech act classifications. In M. Sbisà \& K. Turner (eds.), Pragmatics of speech actions, pp. 173-202. Berlin, Germany: De Gruyter.

Krifka, M. 2015. Bias in commitment space semantics: declarative questions, negated questions, and question tags. In S. D’Antonio, M. Moroney \& C. R. Little (eds.), Proceedings of SALT 25, Washington, pp. 328-345. LSA Open Journal Systems.

Lauer, S. 2013. Towards a dynamic pragmatics. Ph.D. thesis, University of Stanford.

Lewis, D. K. 1969. Convention. Cambridge, MA: Harvard University Press.

Lewis, D. K. 1979. Scorekeeping in a language game. Journal of Philosophical Logic 8. 339-359.

MacFarlane, J. 2011. What is assertion? In J. Brown and H. Cappelen (eds.), Assertion, pp. 79-96. Oxford: Oxford University Press.

Pagin, P. 2014. Assertion. Stanford encyclopedia of philosophy.

Ridge, M. 2006. Sincerity and expressivism. Philosophical Studies 131. 487-510.

Searle, J. R. 1969. Speech acts: An essay in the philosophy of language. Cambridge: Cambridge University Press.

Searle, J. R. 1975. A taxonomy of illocutionary acts. In K. Gunderson (ed.), Language, mind, and knowledge. Minnesota studies in the philosophy of science, vol. 7, pp. 344-369. Minneapolis, MN: University of Minnesota Press.

Searle, J. R. \& D. Vanderveken 1985. Foundations of illocutionary logic. Cambridge: Cambridge University Press.

Segerberg, K. 1984. Towards an exact philosophy of action. Topoi 3.75-83.

Singh, M. P. 2000. A social semantics for agent communication languages. In F. Dignum \& M. Greaves (eds.), Agent communication, Lecture notes in computer science 1916, pp. 31-45. Berlin: Springer.

Soames, S. 1982. How presuppositions are inherited: a solution to the projection problem. Linguistic Inquiry 13. 483-545.

Sperber, D. \& D. Wilson. 1986. Relevance. Oxford: Blackwell.

Stalnaker, R. C. 1973. Presuppositions. Journal of Philosophical Logic 2. 447-457.

Stalnaker, R. C. (1978). Assertion. In P. Cole (ed.), Radical pragmatics. New York: Academic Press.

Stalnaker, R. C. 2002. Common ground. Linguistics and Philosophy 25. 701-721.

Strawson, P. F. 1964. Intention and convention in speech acts. Philosophical Review 73. 439-460.

Vicente, A. \& F. Martinez Manrique. 2011. Inner speech: Nature and functions. Philosophy Compass 6. 209-219.

Walker, R. C. S. 1975. Conversational implicatures. In S. Blackburn (ed.), Meaning, reference and necessity, pp. 133-181. Cambridge: Cambridge University Press.

Walton, D. N. \& E. C. Krabbe. 1995. Commitment in dialogue: Basic concepts of interpersonal reasoning. Albany: State University of New York Press.

Winsler, A. 2009. Still talking to ourselves after all these years: A review of current research on private speech. In A. Winsler, C. Fernyhough \& I. Montero (eds.), Private speech, executive functioning, and the development of verbal self-regulation, pp. 3-41. Cambridge: Cambridge University Press.

Zawidzki, T. W. 2013. Mindshaping: A new framework for understanding human social cognition. Cambridge, MA: MIT Press. 